\title{
Space cannot substitute for time - an integrated experimental assessment of climate-change effects on litter decomposition
}

\author{
Liesbeth van den Brink ${ }^{1}$, Rafaella Canessa ${ }^{2}$, Maaike Bader ${ }^{2}$, Harald Neidhardt ${ }^{3}$, Yvonne \\ Oelmann $^{3}$, Lohengrin Cavieres ${ }^{4}$, and Katja Tielbörger ${ }^{1}$ \\ ${ }^{1}$ University of Tübingen Institute of Evolution and Ecology \\ ${ }^{2}$ University of Marburg \\ ${ }^{3}$ University of Tübingen \\ ${ }^{4}$ Universidad de Concepcion Facultad de Ciencias Naturales y Oceanograficas
}

May 3, 2021

\begin{abstract}
Litter decomposition, a key component of the global carbon cycle, is greatly affected by climate. Unfortunately, our current understanding of climate-change effects on decomposition stems mainly from space-for-time studies along climate gradients, where biotic and climatic effects on litter decomposition are confounded. Experimental studies separating indirect from direct climate effects are needed that test the validity of the space-for-time approach. Here, we combined large- and small scale reciprocal litter translocations, in situ precipitation manipulation, and a prominent climate gradient for studying drought effects on litter decomposition. Interestingly, all experiments indicated clear positive effects of precipitation on decomposition, but the space-for-time approach indicated the opposite, due to indirect climate effects on litter quality. This indicates that space cannot substitute for time and highlights the need for experimental evidence in litter decomposition studies. Such evidence would improve predictions of models of the global carbon cycle that include interactions between climate and vegetation.
\end{abstract}

\section{Hosted file}

van den Brink_Space can-not subsitute for time in litter decomposition.pdf available at https://authorea.com/users/411523/articles/520524-space-cannot-substitute-for-time-anintegrated-experimental-assessment-of-climate-change-effects-on-litter-decomposition 

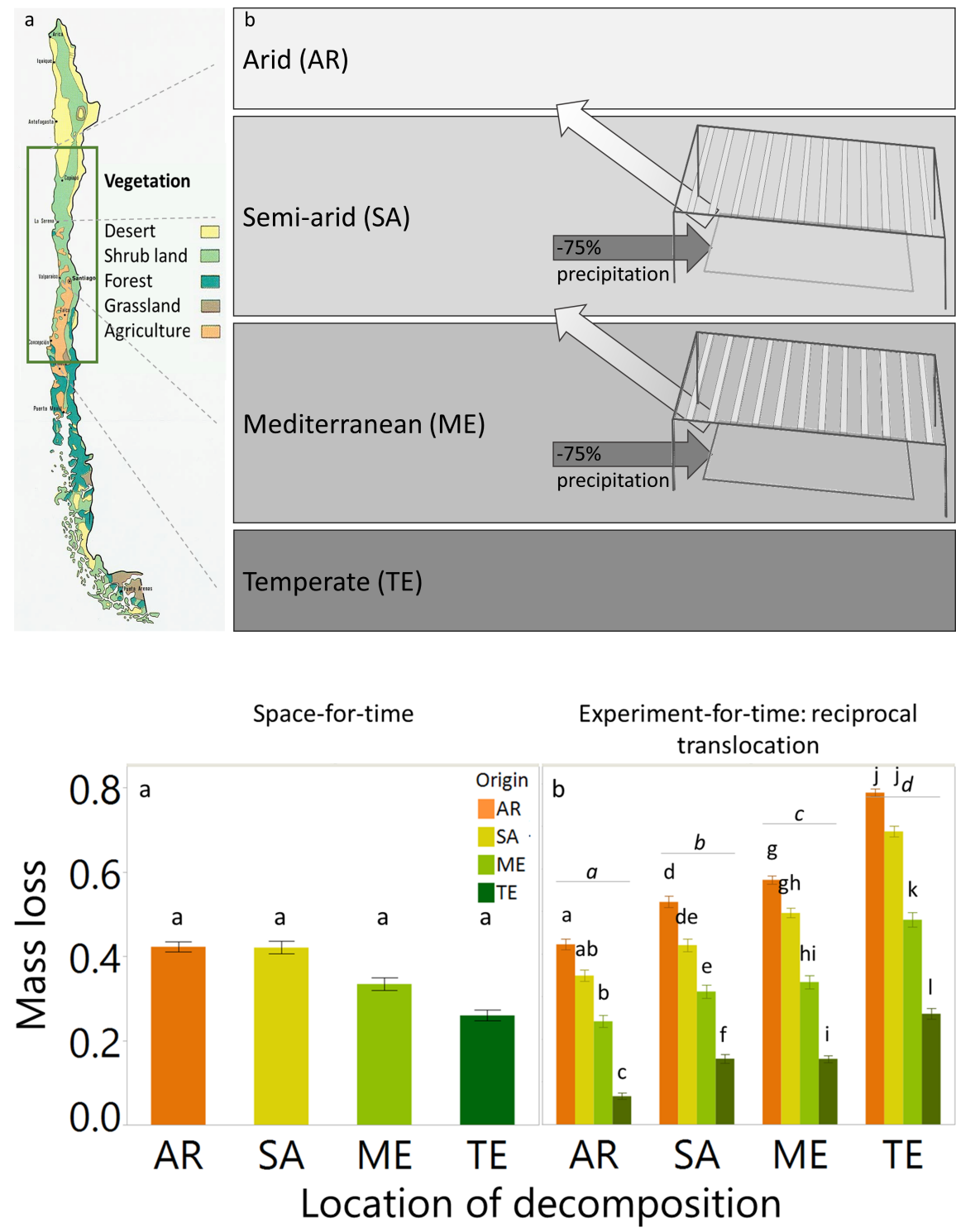

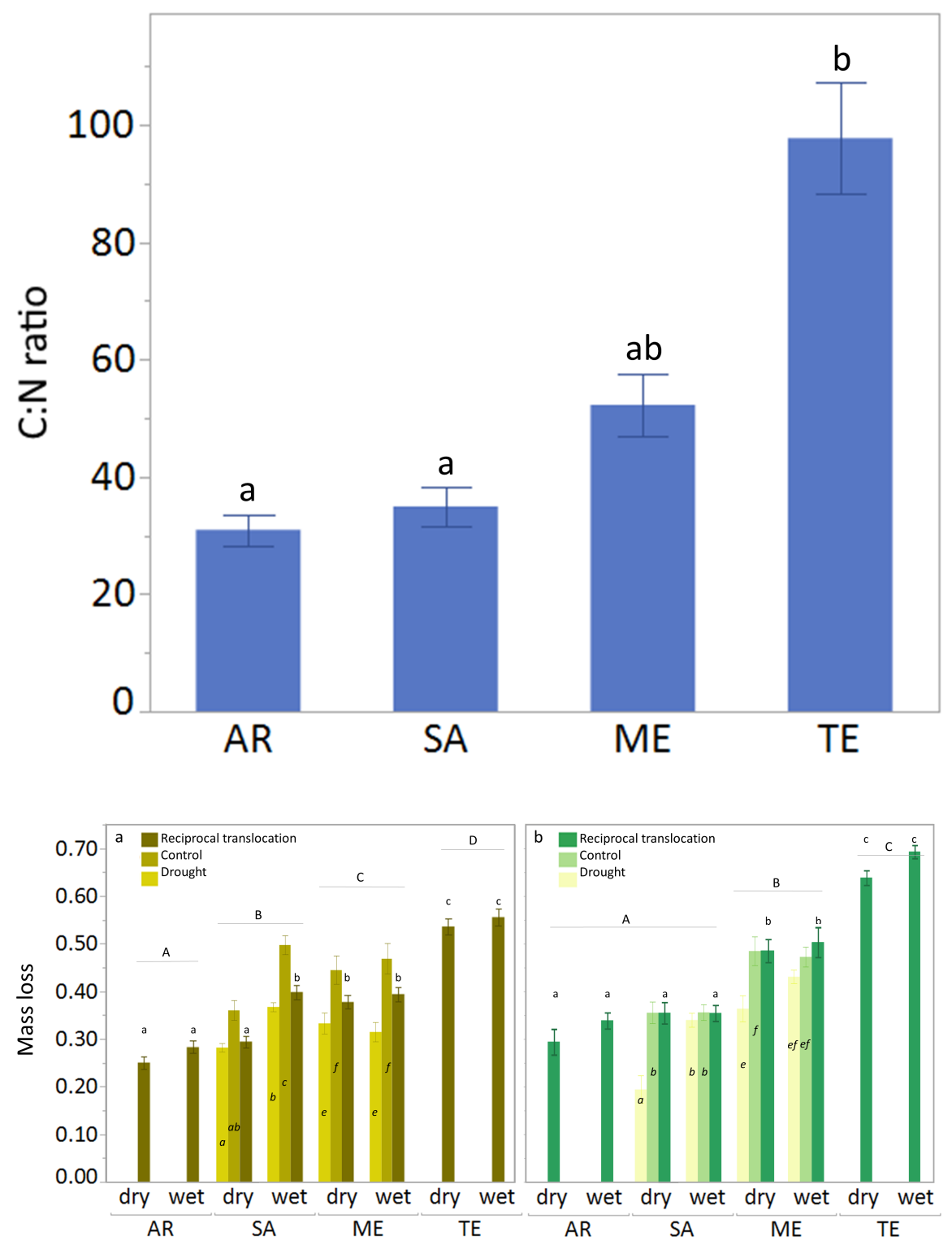